\title{
Structural Equation Modeling and Management Role On The Control of Marek's Disease Outbreaks in Amhara Region Ethiopia
}

Mastewal Birhan ( $\square$ maste675@gmail.com )

University of Gondar https://orcid.org/0000-0002-0984-5582

Nega Berhane

University of Gondar

Molalegne Bitew

Ethiopian Biotechnology Institute

Esayas Gelaye

National veterinary institute

Belayneh Getachew

National veterinary institute

Takele Abayneh

National veterinary institute

Research

Keywords: Economic, Ethiopia, Marek's disease, Risk factors, Structural equation model

Posted Date: November 3rd, 2021

DOI: https://doi.org/10.21203/rs.3.rs-1006948/v1

License: (9) (i) This work is licensed under a Creative Commons Attribution 4.0 International License.

Read Full License 


\section{Abstract \\ Background}

Marek's disease is a highly contagious and economically important oncogenic or paralytic viral disease of poultry and it is becoming a serious problem in the poultry industry of Ethiopia. A questionnaire was designed based on the framework to confirmed how the farm management is reduced the outback of the mark's diseases. Each model construct was measured using a set of rating scale items (questions). A sample size of 200 farmers from different production systems were chosen for data collection. From the analysis, Cornbrash's Alpha (coefficient of reliability) based on the average inter-item correlations were evaluated for each parameter. This structural equation model examines the relationship between risk factors (flock size, litter management, number of staff) and the risk of each farm (numbers of sick, drops in egg production, and the number of death).

\section{Results}

When litter management goes up by 1 , the number of sick goes down by 37.575 , the number of staff goes up by 1 , the number of sick goes down by 7.63 , litter management goes up by 1 , the number of death goes down by 2.505 , flock size goes up by 1 , and the number of death goes down by 0.007 .than the rest of the activities. The result of this structural equation modeling the finding indicates that the data fit the model well (Chi-square $=0.201$, root mean square error of approximation $=0.000$, the comparative fit index $=1.00$, the tucker-lewis coefficient $=1.496$, Degrees of freedom $=2$ ) and the model was appropriated.

\section{Conclusions}

Therefore, it can be concluded that the model must give due attention to the risk factors such as flock size, litter management, number of staff which is different from the previous research result and this might be due to the fact that the effects of environmental factors are more on procurement and integration than the other farm risk factors.

\section{Introduction}

Marek's disease (MD) may be an international threat to poultry production and is characterized by malignant neoplastic disease development in visceral organs and nerves, leading to paralysis and death in inclined chickens (Othman and Aklilu, 2019). So, so as to advance management strategy of Marek's diseases in poultry would force totally different methods: as an example higher application of the presently accessible tools, that is embrace acceptable measures of biosecurity, acceptable vaccination practices, and management of alternative immunological disorder viruses (Gimeno, 2004). For the higher 
and also the best choices to stop the Marek's diseases is that the vaccines have brought monumental advantages to poultry production (Bublot and Sharma, 2004).

After the isolation of Marek's sickness herpesvirus (MDV) within the late Nineteen Sixties the primary vaccines were developed in England (Schat, 2016) and conjointly at the tip of Nineteen Sixties, us Department of Agriculture (USDA) had established the fundamental purity and safety standards for poultry biologics (Espeseth and Lasher, 2013). Despite over forty years of usage, the precise mechanism(s) of MD vaccine-related immunity and anti-tumor effects don't seem to be proverbial (McPherson et al., 2016). All vaccines, with the exception of the cell-free lyophilized HVT, have to be administered parentally in the form of living infected cells. Under field conditions, exposure to field virus occurs early in life requiring immunity in the young bird (Zhou et al., 2019). For this reason vaccination takes place at one day of age (Şandru et al., 2008). Vaccinal protection against MD is complicated and influenced by several factors. These embrace the host genotype which may influence each host susceptibleness to MD and responsiveness to vaccination (Bavananthasivam et al., 2018).

Quantification of patterns of viral shedding and virus-induced host mortality are necessary for a rigorous understanding of the epidemiology of a disease, not least to identify increases in virulence (Atkins et al., 2011). The disease is an airborne poultry pathogen primarily affecting chickens and causing losses to the industry of $\$ 1-2$ billion annually (Atkins et al., 2013).

The virus is then transferred by the bloodstream in alveolar macrophages to B and T lymphocytes. After the primary infection stage, between 7 and 14 days postinfection (dpi), MD may become latent in infected lymphoid cells, which proliferate in different parts of host, especially in the liver, spleen, kidney, proventriculus and ovaries. This leads to tumour formation after reactivation of the virus to the transformation stage. Subsequently, the virus is then transferred to the environment as fine particles of skin and feather debris (Woźniakowski and Samorek-Salamonowicz, 2014). The direct relationship between MDV strains of higher pathogenicity and greater immunosuppression (Li et al., 2011).

Indigenous chickens kept under village, scavenging production systems represent $97 \%$ of the chickens farmed in Ethiopia. In this system, micro- and macro-parasitic infectious diseases, combined with limited extension and veterinary services, are major constraints to village chicken production. Poor management and limited resources hinder the development of chicken production by reducing outputs and by predisposing to disease outbreaks (Luu et al., 2013). Increased productivity of the poultry subsector by using exotic breeds in Ethiopia failed to become a sustainable option mainly because this strategy recurrently faced the problem of birds not being adopted widely by the rural farmers due to several socioeconomic and environmental challenges. The management conditions under which the animals are produced vary along the existing production systems which were broadly classified into the village, smallscale commercial, and large-scale commercial systems based on flock size, production objectives, and level of specialization and/or technology use (Dana et al., 2010). Among the impediments of the poultry development in this country constitute diseases like Marek's disease with frequent outbreaks and presenting a serious threat and challenge to the young growing poultry industry in Ethiopia. Therefore, the 
objectives of this study were, to explore the relationships between farm size, litter management and number of staff as a risk factors for their contribution to develop risk, egg production loss and chicken death that intentions to implement MD control measures in the different chicken production systems of Ethiopia, and to identify potential management factors about the disease and its control measures that influence the intentions to implement control measures using the SEM framework.

\section{Materials And Methods}

\section{Theoretical Framework}

The basic concept of SEM is a powerful, multivariate technique found increasingly in scientific investigations to test and evaluate multivariate causal relationships. The key in the regression analysis is to determine how much of the change in the dependent variable is explained by the independent variable or variables. Although multiple regression analysis can only be applied to observed variables, the basic principles can be applied to structural equation modeling (Kline, 2011).

As a new statistical analysis technique, allows testing research hypotheses in a single process by modeling complex relationships among many observed and latent variables. However, in the method of structural equation modeling, direct and indirect effects are put together. The researcher develops hypotheses about the relationships among variables that are based on theory, previous empirical findings, or both. These relationships are direct or indirect whereby intervening variables mediate the effect of one variable on another. This researcher also determined the relationships are unidirectional or bidirectional, by using previous research and theoretical predictions as a guide. The researcher outlines the model by determining the number and relationships of measured and latent variables (Beran and Violato, 2010).

1. Supposed flock size about the likelihood of getting a MD disease, reduced egg production or increased the death rate,

2. Perceived number staff in ability of the advised action to reduce MD threat i.e. susceptibility and severity, and

3. Patterns of correlation among a set of litter management of the recommended action for the control of MD.

4. Confirms the correspondence of the data of the relations in the theoretical model.

Thinking of SEM as a combination of factor analysis and path analysis sets the researcher up for thinking about SEM's two primary components: the measurement model and the structural model. The measurement model of SEM allows the researcher to evaluate how well his or her observed (measured) variables combine to identify underlying hypothesized constructs. Confirmatory factor analysis is used in testing the measurement model, and the hypothesized factors are relationships between flock size, litter 
management (LM), number of staff and between numbers of sick, drop in egg production (DEP), number of death.

As shown in figure 15, the first observed, endogenous variables (Number of sick, drop in the egg of production, Number of death) is linked to the observed, exogenous variables (flock size, litter management, number of staff), and unobserved, exogenous variables (e1, e2 and e3) (Question 1, Question 2, and Question 3) which are composed of the questions answered in the research questionnaire. In the figure, the number of variables in this model: Umber of observed variables (9), number of unobserved variables (3), number of exogenous variables (6), and number of endogenous variables (3) in figure (1).

Question $1=\lambda 1 \cdot X+e 1$

Question $2=\lambda 2 . X+e 2$

Question $3=\lambda 3 . X+e 3$

\section{Questionnaire Design}

A questionnaire was designed based on the framework described above. Each model construct was measured using a set of rating scale items (questions). The supposed flock size about the likelihood of getting MD disease, reduced egg production, or increased the death rate, was elicited by three rating questions. The first question assessed the frequency of MD outbreaks as experienced in different farms' flock sizes. The second question referred to the experienced frequency in the small flock size $(<50)$. Both questions were answered on a four point rating scale, which indicated the occurrence of having an outbreak every $<50,51-1000,1000-10,000$, or $>10001$ chicken flock. The third question measured the chicken flock size associate with MD occurrence by a three points rating scale (high, medium, low). The perceived number of staff or ability was measured using two rating questions on a three points scale (large, medium, and small):

One the question was about the impact of MD relative to general chicken egg production problems and the other question about the impact of MD relative to the impact of other poultry diseases. The patterns of correlation among a set of litter management of the advised action for the control of MD was measured by two rating scale questions on a three points scale (high, medium, low) for the proposed control measures related to litter management, and influence chicken performance and important for the welfare chicken. To confirms the correspondence of the data of the relations in the theoretical model for the control of MD. The objectives were weighed for three suggested specific MD control measures, including 1) management of chicken at farm level, 2) MD vaccine address, 3) biosecurity of chicken farms.

\section{Data Collection}

\section{Chicken Production systems}


Poultry production has a major role in the economy of developing countries, including an important role in poverty alleviation by means of income generation and household food security. More than half of Ethiopian households both in rural and urban areas keep chickens, although there is considerable variation in the distribution of chicken keeping, with most households in highland areas keeping chickens, and far fewer doing so in lowland pastoral areas (Sambo et al., 2015). Whilst village chickens are widely accessible and require few inputs, productivity is low and constrained by, among other things, disease, predation and scarcity of feed. Interventions to improve production include vaccination; bird distribution; management interventions; cross-breeding programs; and combined programs, but few interventions have been demonstrably sustainable in village chicken production systems (Bettridge et al., 2018).

Chicken production is an integral part of most rural families' livelihoods (an estimated two-thirds of Ethiopian villagers keep poultry) and birds are commonly kept at night on perches within the family dwelling, frequently in the kitchen (Brena et al., 2016). Poultry industry in Ethiopia is infant but fast growing sector. The industry faces various challenges such as shortage of feed in terms of quality and quality, poor husbandry practices, prevalence, and wide distribution of infectious and noninfectious diseases. Poor veterinary services and lack of appropriate breeding practices are assumed to be additional challenges. Moreover, the government has given less attention. Disease is resulting in as high as $20-50 \%$ estimated mortality rate ranges (Berhe et al., 2019).

\section{Sampling}

A sample size of 200 farmers from different production system, was chosen for data collection. This sample size was based on a pragmatic consideration of SEM feasibility and reasonable power of test for the intended statistical analyses, In addition, the minimum sample size for structural equation modeling is suggested as 15 (Bentler and Chou, 1987), and Some researchers suggest that the sample size for SEM should be 200-500, at least 200 (Çelik and Yılmaz, 2013). The farmers were sampled from 11 zones (North Shewa, North Gondar, East Gojjam, Central Gondar, Awi, West Gojjam, West Gondar, South Gondar, Bahir Dar, South Wollo, and North Wollo) in the both intensive and extensive farming system. Selection of zones and cities was based on the authors' subjective judgment of representativeness of the production systems and on convenience of accessibility. The difference in the number of zones sampled from the different production systems was a reflection of the proportion of zones in the different production systems. This selection procedure was continual in other zones until the required sample size (200) for each sub-city was reached.

The questionnaire was prepared in English and translated into Amharic language for all administration zones. It was directed to the selected farmers and farm owners by face to face interviews. The study proposal was ethically reviewed and approved by the Institutional Review Board of the University Gondar. Oral informed consent was obtained from each participating farmer after reading a written consent form. The use of oral consent was approved by the Institutional Review Board considering the fact that most of the study participants could not read and write to give their consent in writing. The interviewers confirmed 
the participants' oral consent by signing on the respective consent form for each interview as per the Board's guideline.

\section{Model Specification}

In the present study, the six basic constructs of the SEM were used to assess farm owner perceptions of MD and its control in North West Ethiopia. In the evaluation of the effect of these factors on the motivation of farm owners to implement control measures against the disease by improving farm management, the intention to participate in hypothetical MD control measures was considered as a proxy of the actual behavior. This is due to absence of any official control in practice to measure the behavior directly. Although intention does always explain to farm management system was always related to disease outbreak. In the analysis, socio-demographics and husbandry variables were used as modifying factors of the perception.

Furthermore, supposed the preliminary study has hypothesized the measurement model described the relationships among these six variables in Figure 15. This has described a model that can be accounted for the observed relationships between flock size, litter management (LM), number of staff and between the number of sick, drop in egg production (DEP), number of death (both were indicators of their respective correlated factors). However, that there was a moderated relationship between all variables. Our model was accounted for the risk factor relationship. In essence, these has created a model that says the relationship between flock size, litter management (LM), and the number of staff and between the numbers of sick, drop in egg production (DEP), a number of death is equal to 1.0 to scale latent variables. Our model determined to the extent that the relationships hypothesized was captured the observed relationships on the parameter path (Kline, 2005).

\section{Data Analysis}

The valuations of this model were to endorse appropriate poultry health management to control the emergence of highly pathogenic diseases like MD and measures bio-security for better performance and quality of poultry production in a competitive world. Analyses of the management skills of poultry production to evaluate the proposed risk factor correlation to the occurrence and the reduction of poultry product by MD. By measures, the management risk factor to control the disease was performed in North West Ethiopian situation.

There are 13 correlation coefficients between the variables that used in the SEM, the number of staff, LM, FS, number of sick, number of death, DEP and LM. Likewise, there are correlation coefficient between number of staff, LM, FS, number of sick, number of death, DEP and LM, the commonly applied threshold significant value of 0.05. Each factor was then evaluated using a separate Factor Analysis (FA). From the analysis, Cronbach's Alpha (coefficient of reliability) based on the average inter-item correlations are evaluated for each parameter. The quantitative data was purified and analyzed using Statistical Package for Social Science (SPSS) version 20 and Analysis of Moments Structures (AMOS) version 18 were used to analyses the confirmatory factor analyze, reliability test, descriptive statistics, Pearson Correlation, and path analysis. 


\section{Results}

\section{Variables Summery}

The observed variable (manifest variable) is the measured variable in the data collection process; latent variables are variables that are measured by connecting to observed variables because they cannot be directly measured. Latent variables must be represented by more than one observed variable since they represent abstract concepts. Latent variables represent hypothetical constructs in a research model (Raykov, 1997). In the case of this study, the model has the following observed or endogenous variables: the number of sick, drop in egg production (DEP), and the number of death. Observed or exogenous variables: flock size (FS), litter management (LM), number of staff, and unobserved or exogenous variables: e1, e2, and e3. The variable counts are also: number of variables in the model (9), number of observed variables (6), number of unobserved variables (3), number of unobserved variables (3), number of exogenous variables (6), and number of endogenous variables (3). The Number of distinct sample moments (21), the number of distinct parameters to be estimated (19), and degrees of freedom (2).

The skewness and kurtosis values are examined to determine whether the variables in the data set are normally distributed. It is sufficient to mark the "test for normality" and "outliers" options so that these test values can be obtained in a tabular form (Sarstedt and Mooi, 2014). This is because tests such as these are highly sensitive to sample size, with larger sample sizes being more likely to produce significant results. In light of this, it is recommended that the significance tests be used in conjunction with descriptive statistics, namely the kurtosis values for individual variables (Pituch and Stevens, 2015). Kurtosis values less than 3.00 in magnitude may indicate that a variable is normally distributed (Westfall and Henning, 2013). So, the result of this SEM was normally distributed. The reliability of the new and modified items was tested carefully before evaluating the research model. In order to have a valid construct in the model, each of the items comprising the model was checked to see if it was unidimensional, since this would have help to produce a consistent result.

\section{Normality Test}

To determine whether univariate normality exists, the model examines the distribution of each observed variable for skewness and kurtosis. Skewness is the degree to which a variable's distribution is asymmetrical, with positive skew describing a distribution where many scores are at the low end of a scale (the score distribution for a very difficult test). For the skewness index, absolute values greater than 3.0 are extreme (Chou \& Bentler, 1995). Kurtosis is an index of the peak and tails of the distribution. Positive kurtosis reflects very peaked distributions (leptokurtic), with short, thick tails (also called heavytailed distributions) representing few outliers. Negative kurtosis exists when the distribution is quite flat (mesokurtic), with long, thin tails, indicating many outliers. Absolute values higher than 10.0 for the kurtosis index suggest a problem, and values higher than 20.0 are extreme (Kline, 2005). Univariate normality is especially important to consider because distributions can vary from normality in at least four ways. In our model all variables were positively skewed (Table 1). 
Table 1

Assessment of normality

\begin{tabular}{|lllllll|}
\hline Variable & min & max & skew & c.r. & kurtosis & c.r. \\
\hline No. Staff & 2 & 10 & 1.252 & 7.229 & 1.047 & 3.023 \\
\hline LM & 1 & 3 & 0.812 & 4.685 & -0.602 & -1.737 \\
\hline FS & 200 & 3000 & 1.222 & 7.056 & 1.401 & 4.044 \\
\hline No. Sick & 10 & 1876 & 2.481 & 14.323 & 9.395 & 27.122 \\
\hline No. Death & 2 & 1868 & 2.594 & 14.976 & 10.08 & 29.099 \\
\hline DEP & 8 & 1874 & 2.607 & 15.053 & 10.178 & 29.382 \\
\hline Multivariate & & & & & 259.285 & 187.123 \\
\hline
\end{tabular}

\section{Sample Moments}

On table (2) the covariance statistical result shows and determines the relationship between the movement of observed and latent variable asset prices. When two variables tend to move together, they are seen as having a positive covariance; when they move inversely, the covariance is negative. Hence, based on the model result, except the relationship between number of staff and LM, between FS and LM, between number of sick and LM, between number of death and $L M$, between DEP and $L M$, all are positive relationship.

Table 2

Covariance's result on observed and latent variable

\begin{tabular}{|lllllll|}
\hline & No. Staff & LM & FS & No. Sick & No. Death & DEP \\
\hline No. Staff & 3.316 & & & & & \\
\hline LM & -0.019 & 0.494 & & & & \\
\hline FS & 657.507 & -17.159 & 286017 & & & \\
\hline No. Sick & 168.391 & -23.468 & 79575.2 & 66581.68 & & \\
\hline No. Death & 162.648 & -24.132 & 76424.3 & 64863.972 & 65356.038 & \\
\hline DEP & 163.039 & -23.534 & 77015.7 & 64918.483 & 64907.52 & 65064.618 \\
\hline
\end{tabular}

Correlation is the coefficient that indicates the power of linear relationship between variables. This coefficient must be statistically significant in order to be able to say that there is a relationship between variables. The correlation coefficient takes a value between -1 and +1 (Sipahi et al., 2010). All the 
variables that used in the SEM, the number of staff, LM, FS, number of sick, number of death, DEP and $L M$, all are positive relationship.in the positive direction (+1). Therefore, linearity, which is the most important assumption of regression analysis, also applies to structural equation modeling. The sample correlation coefficient result in the model showed liner relationship between dependent and in dependent variable (Table 3). Direct effect is the effect of one variable on another variable without any mediation. However, the indirect effect arises from the intervention of a variable which is playing mediator role between independent and dependent variables (Raykov and Marcoulides, 2006).

Table 3

Correlations and mean result on dependent and in dependent variable of SEM

\begin{tabular}{|llllllll|}
\hline & No. Staff & LM & FS & No. Sick & No. Death & DEP & Mean \\
\hline No. Staff & $1^{*}$ & & & & & 3.685 \\
\hline LM & -0.015 & $1 *$ & & & & 1.575 \\
\hline FS & 0.675 & -0.046 & $1^{*}$ & & & 951.45 \\
\hline No. Sick & 0.358 & -0.129 & 0.577 & $1^{*}$ & & 268.51 \\
\hline No. Death & 0.349 & -0.134 & 0.559 & 0.983 & $1^{*}$ & & 253.82 \\
\hline DEP & 0.351 & -0.131 & 0.565 & 0.986 & 0.995 & $1^{*}$ & 260.25 \\
\hline
\end{tabular}

\section{Parameter Estimation, Model Evaluation, and Model Comparison}

\section{Maximum likelihood estimates}

The regression weight estimate result indicates that, when LM goes up by 1 , number of sick goes down by 37.575 , number of staff goes up by 1 , number of sick goes down by 7.63 , LM goes up by 1 , number of death goes down by 2.505 , FS goes up by 1 , number of death goes down by 0.007 .than the rest of the activities. The probability of getting a critical ratio as large as 7.811 in absolute value is less than 0.001 . In other words, the regression weight for FS in the prediction of number of sick was significantly different from zero at the 0.001 level (two-tailed). 
Table 4

Regression weights estimate and critical ratio of SEM on impact of risk

\begin{tabular}{|lllllll|}
\hline & Path & & Estimate & S.E. & C.R. & P \\
\hline No. Sick & $<--$ & FS & 0.294 & 0.038 & 7.811 & $* \star *$ \\
\hline No. Sick & $<--$ & LM & -37.575 & 21.086 & -1.782 & 0.075 \\
\hline No. Sick & $<--$ & No. Staff & -7.63 & 11.026 & -0.692 & 0.489 \\
\hline No. Death & $<--$ & No. Sick & 0.98 & 0.016 & 62.216 & $* * *$ \\
\hline No. Death & $<--$ & LM & -2.505 & 4.724 & -0.53 & 0.596 \\
\hline No. Death & $<--$ & FS & -0.007 & 0.01 & -0.763 & 0.445 \\
\hline No. Death & $<--$ & No. Staff & 0.701 & 2.454 & 0.286 & 0.775 \\
\hline DEP & $<--$ & No. Sick & 0.224 & 0.034 & 6.606 & $* * *$ \\
\hline DEP & $<--$ & FS & 0.001 & 0.004 & 0.398 & 0.691 \\
\hline DEP & $<--$ & No. Death & 0.769 & 0.034 & 22.798 & $* * *$ \\
\hline
\end{tabular}

In this section, the findings of the model are presented in (Table 4). Regarding the variables the between FS and LM was estimated to be (-17.159) and between LM and number of staff is estimated to be (-.019), they were indicted inverse consequence, the other were positive effect to risk and disease causing factors.

Table 5 Maximum likelihood estimates from the SEM relationship between variable A) Covariances

\begin{tabular}{|c|c|c|c|c|c|c|}
\hline & & & Estimate & S.E. & C.R. & $\mathbf{P}$ \\
\hline FS & $<->$ & LM & -17.159 & 26.684 & -0.643 & 0.52 \\
\hline FS & $<->$ & No.Staff & 657.507 & 83.295 & 7.894 & $\star * *$ \\
\hline LM & $<->$ & No.Staff & -0.019 & 0.091 & -0.208 & 0.835 \\
\hline
\end{tabular}

B) Variances 


\begin{tabular}{|lllll|}
\hline & Estimate & S.E. & C.R. & P \\
\hline FS & 286016.508 & 28673.424 & 9.975 & $* * *$ \\
\hline LM & 0.494 & 0.05 & 9.975 & $* \star *$ \\
\hline No. Staff & 3.316 & 0.332 & 9.975 & $* \star *$ \\
\hline e1 & 43628.99 & 4373.847 & 9.975 & $* * *$ \\
\hline e2 & 2155.264 & 216.067 & 9.975 & $* * *$ \\
\hline e3 & 488.983 & 49.021 & 9.975 & $* * *$ \\
\hline
\end{tabular}

\section{C) Correlations}

\begin{tabular}{|c|c|c|c|}
\hline & & & Estimate \\
\hline FS & <-> & LM & -0.046 \\
\hline FS & <-> & No. Staff & 0.675 \\
\hline LM & $<->$ & No. Staff & -0.015 \\
\hline
\end{tabular}

\section{Matrices Factor Score Weights Estimates}

The other issue is the direct effect of an independent variable (exogenous) on a dependent variable (endogenous) as reported on (Table 5). The findings of the results showed that the between number of death and LM, FS, and number of staff were not all statistically significant ( $p>0.05)$. The other issue is the indirect effect of an independent variable (exogenous) on a dependent variable (endogenous) as reported on (Table 6). The findings of the results showed that the between number of death and LM, FS, and number of staff were not all statistically significant $(p>0.05)$. The number of staff and LM were increased by one the number of sick increased (-7.63 and -37.575 , individually), or number of staff and LM was related negatively to number of sick but number of staff and LM were related positively to the FS (0.294), and LM and FS were negatively affect the number of death (-2.505 and -0.007 , respectively), but number of staff was positively related to the number of death (0.701). The number of staff, LM and FS were positively correlated to DEP. number of staff, LM and FS were increased by one the DEP significantly increased by one $\left.{ }^{(\star \star \star}\right)$. 
Table 6

Factor score weights estimates from the SEM between dependent and in dependent variable

\begin{tabular}{|c|c|c|c|c|c|}
\hline \multicolumn{6}{|c|}{ A) Direct Effects } \\
\hline & No. Staff & LM & FS & No.Sick & No. Death \\
\hline No. Sick & -7.63 & -37.575 & 0.294 & $\star \star \star$ & $\star \star \star$ \\
\hline No. Death & 0.701 & -2.505 & $-0.007 *$ & 0.98 & 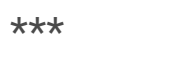 \\
\hline DEP & $\star \star \star *$ & $\star \star \star$ & $0.001 *$ & 0.224 & 0.769 \\
\hline \multicolumn{6}{|c|}{ B) Indirect Effects } \\
\hline & No. Staff & LM & FS & No. Sick & No. Death \\
\hline No. Sick & $\star \star \star$ & $\star \star *$ & $\star \star \star \star ~$ & $\star \star \star ~$ & 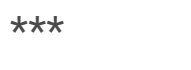 \\
\hline No. Death & -7.48 & -36.833 & 0.288 & $\star \star \star \star ~$ & 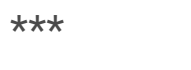 \\
\hline DEP & -6.923 & -38.674 & 0.281 & 0.754 & $\star \star \star ~$ \\
\hline \multicolumn{6}{|c|}{ C) Total Effects } \\
\hline & No. Staff & LM & FS & No. Sick & No. Death \\
\hline No. Sick & -7.63 & -37.575 & 0.294 & $\star \star \star *$ & $\star \star \star ~$ \\
\hline No. Death & -6.778 & -39.338 & 0.28 & 0.98 & 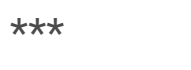 \\
\hline DEP & -6.923 & -38.674 & 0.283 & 0.978 & 0.769 \\
\hline
\end{tabular}

\section{Model Fit Summary}

All of the risk factors, all the variables that used in the SEM, the number of staff, LM, FS, number of sick, number of death, DEP and LM cause the risk the total number of the respective items and the data fits the model reasonably well (Table 7). In the method of structural equation modeling, the measures that assess the compliance of the models with the data are called fit indices or fit statistics. There are many fit indices in the literature. Below there are definitions of the most commonly used of these fit indices? The size of the sample were considered in the analyzes to be done by the structural equation modeling. Because many of the fit indices are affected by sample size (Jayaram et al., 2004). 
Table 7

SEM of the model fit summary in all variable

\begin{tabular}{|c|c|c|c|c|c|c|c|c|}
\hline Model & DF & $\mathbf{P}$ & CMIN/DF & RMR & GFI & AGFI & PGFI & RMSEA \\
\hline DM & 2 & 0.904 & 0.101 & 0.171 & 1 & 0.996 & 0.095 & \\
\hline SM & & & & & 1 & & & 0.786 \\
\hline $\mathrm{IM}$ & 15 & & 123.878 & 38259.5 & 0.386 & 0.14 & 0.276 & \\
\hline
\end{tabular}

\section{Discussion}

Marek's disease is a disease of chickens produced by a herpesvirus that produces a reduction in the immune response in acutely infected chicken followed by the production of tumors in many of the infected birds. Very virulent strains (VvMDV+) have been reported in a number of countries around the world and have affected broilers, breeders and commercial layers. This disease extensively limits the productivity of both egg producing and meat producing birds resulting in great economic impact in poultry industry. Vaccination, in conjunction with good farm cleaning and disinfection, proper reception practices, adequate downtime between flocks, all-in-all-out policy, accurate vaccination programs adapted to the type of bird and field situation, good vaccine preparation and administration practices and strict biosecurity measures can greatly reduce the incidence of MD and thereby prevent the economic losses due to the disease. In problematic areas with monovalent vaccine, bivalent or polyvalent vaccine is recommended for the effective prevention of virulent MD. However, vaccine failures do occur as field strains continue to evolve towards pathotype of greater virulence. The constant evolution of MD has pressed us for the development of new vaccines or vaccine strategies that control the more virulent emerging strains. However, the competition between the development of vaccines and evolution of MD is a major threat for poultry industry (Purchase and Biggs, 1967).

AMOS would have to provide this coefficient and a corresponding "critical value" which can be interpreted as a significance test (a critical value of 1.96 corresponds to a p-value of .05). If Mardia's coefficient is significant, (i.e., the critical ratio is less than 1.96 in magnitude) the data are be normally distributed. In this SEM, where the sample size is expected to be very large, this means that Mardia's coefficient is almost always guaranteed to be significant. Thus, the significance test on its our does provide very useful information. In light of this, it is recommended that the significance tests be used in conjunction with descriptive statistics, namely the kurtosis values for individual variables (Pituch and Stevens, 2015). Kurtosis values less than 3.00 in magnitude may indicate that a variable is normally distributed (Westfall and Henning, 2013). Hince, this SEM result was normally distributed.

Previously, guidelines for acceptable fit included a non-significant CFI greater than 0.90 (Hu and Bentler, 1995), RMSEA less than 0.10 with a maximum upper bound of the $90 \% \mathrm{Cl}$ of 0.10 (dan Cudek, 1993). 
Although many still follow these guidelines (as evidenced by the positive evaluation of models with fit indices at or near these values), readers should be aware that debate exists among statisticians (and likely among reviewers) regarding acceptable fit. Recent studies (Hu and Bentler, 1998) have suggested a maximum cutoff of 0.06 for RMSEA. Although, the result of this SEM, LM, FS and number of staff engaged a total and the finding indicates that the data fits the model well $(\chi 2=0.201, \mathrm{RMSEA}=0.000, \mathrm{CFI}$ $=1.00, \mathrm{TLI}=1.496)$.

From the analysis, Cronbach's Alpha (coefficient of reliability) based on the average inter-item correlations are evaluated for each parameter. Except FS, each item under each constructs has correlated item-total correlation of $\geq 0.80$. In addition, the Cronbach Alpha value for FS were greater than 0.80 . When FS goes up by 1 , number sick goes up by 0.294 , when number sick goes up by 1 , number of death goes up by 0.98 , when number of staff goes up by 1 , number of death goes up by 0.701 , when FS goes up by 1 , DEP goes up by 0.001 , when number of death goes up by 1 , DEP goes up by 0.769 .

\section{Conclusion}

As a result, the model FS and number of staff were showed significant effect on the risk of chicken farm industry (DEP, number of sick and number of death increased). This model is conducted to identify vital in observed or exogenous variables: flock size (FS), litter management (LM), number of staff, activities which have more impact on the numbers of sick, drops in egg production (DEP), and the number of death. The research uses questionnaires to assess different farms from different zones such as construction, infrastructure, feeding status, vaccine access and research and development model in Ethiopia. From the literature, three different input factors (flock size, litter management, number of staff) were identified that affect the impact of numbers of sick, drops in egg production, and the number of death used to study the effects of different risk factors on the farming activities. Afterward, the relationship between each of the risk factors and the farm risks were studied. Therefore, it can be concluded that the model must give due attention to the risk factors such as flock size, litter management, number of staff which is different from the previous research result and this might be due to the fact that the effects of environmental factors is more on procurement and integration than the other farm risk factors.

\section{Declarations}

\section{Data sharing statement}

Data will be made available upon request of the primary author.

\section{Ethics statement}

For the research team members to conduct the current study, after permitted ethical approval and statement given by the University of Gondar, Ethiopia. The current study was reviewed by the Institutional Ethical Review Board of the University of Gondar for its ethical soundness, and it is found to be ethically 
acceptable. Thus, the Research and Community Service Vice President Office has awarded on R. No. O/V/PRCS/05/495/2018.

\section{Funding}

This Ph.D. work was supported by the University of Gondar (Institute of Biotechnology), research and community service vice president office, Ethiopian. Moreover, material and financial provisions were sponsored by National Veterinary Institute and Ethiopian Biotechnology Institute together.

\section{Authors' contributions}

Mastewal Birhan, Nega Berhane, Molalegne Bitew, Esayas Gelaye, and Takele Abayneh are substantial contributors to the conception and design, acquisition of data, or analysis and interpretation of data, drafting the article or revising it critically for important intellectual content. Belayneh Getachew and Mastewal Birhan are given some technical comments. Mastewal Birhan, Nega Berhane, Molalegne Bitew, Esayas Gelaye, and Takele Abayneh approved the final draft of the manuscript to be published and agreed to be accountable for all aspects of the work in ensuring that questions related to the accuracy or integrity of any part of the work are appropriately investigated and resolved.

\section{Disclosure}

The authors declare that they have no competing interests for this work.

\section{References}

1. Atkins, K. E., Read, A. F., Savill, N. J., Renz, K. G., Walkden-Brown, S. W. \& Woolhouse, M. E. 2011. Modelling Marek's Disease Virus (Mdv) Infection: Parameter Estimates For Mortality Rate And Infectiousness. Bmc Veterinary Research, 7, 1-12.

2. Atkins, K. E., Read, A. F., Walkden-Brown, S. W., Savill, N. J. \& Woolhouse, M. E. 2013. The Effectiveness Of Mass Vaccination On Marek's Disease Virus (Mdv) Outbreaks And Detection Within A Broiler Barn: A Modeling Study. Epidemics, 5, 208-217.

3. Bavananthasivam, J., Read, L., Astill, J., Yitbarek, A., Alkie, T. N., Abdul-Careem, M. F., Wootton, S. K., Behboudi, S. \& Sharif, S. 2018. The Effects Of In Ovo Administration Of Encapsulated Toll-Like Receptor 21 Ligand As An Adjuvant With Marek's Disease Vaccine. Scientific Reports, 8, 1-9.

4. Bentler, P. M. \& Chou, C.-P. 1987. Practical Issues In Structural Modeling. Sociological Methods \& Research, 16, 78-117.

5. Beran, T. N. \& Violato, C. 2010. Structural Equation Modeling In Medical Research: A Primer. Bmc Research Notes, 3, 1-10.

6. Berhe, M., Mekibib, B., Bsrat, A. \& Atsbaha, G. 2019. Gastrointestinal Helminth Parasites Of Chicken Under Different Management System In Mekelle Town, Tigray Region, Ethiopia. Journal Of Veterinary Medicine, 2019. 
7. Bettridge, J. M., Psifidi, A., Terfa, Z. G., Desta, T. T., Lozano-Jaramillo, M., Dessie, T., Kaiser, P., Wigley, P., Hanotte, O. \& Christley, R. M. 2018. The Role Of Local Adaptation In Sustainable Production Of Village Chickens. Nature Sustainability, 1, 574-582.

8. Brena, M., Mekonnen, Y., Bettridge, J., Williams, N., Wigley, P., Tessema, T. S. \& Christley, R. 2016. Changing Risk Of Environmental Campylobacter Exposure With Emerging Poultry Production Systems In Ethiopia. Epidemiology \& Infection, 144, 567-575.

9. Bublot, M. \& Sharma, J. 2004. Vaccination Against Marek's Disease. Marek's Disease. Elsevier.

10. Çelik, H. \& Yılmaz, V. 2013. Lisrel 9.1 Ile Yapısal Eşitlik Modellemesi (Yenilenmiş 2. Baskı). Ankara: Anı Yayıncılık.

11. Dan Cudek, B. 1993. Alternative Ways Of Assessing Model Fit. Ka Bollen Dan J. Scott Long (Editors). Testing Structural Equation Model. Sage Publication.

12. Dana, N., Van Der Waaij, L. H., Dessie, T. \& Van Arendonk, J. A. 2010. Production Objectives And Trait Preferences Of Village Poultry Producers Of Ethiopia: Implications For Designing Breeding Schemes Utilizing Indigenous Chicken Genetic Resources. Tropical Animal Health And Production, 42, 15191529.

13. Espeseth, D. A. \& Lasher, H. 2013. History Of Regulatory Requirements For Poultry Biologics In The United States, 1970s To 1990s. Avian Diseases, 57, 167-171.

14. Gimeno, I. M. 2004. Future Strategies For Controlling Marek's Disease. Marek's Disease. Elsevier.

15. Hu, L.-T. \& Bentler, P. M. 1995. Evaluating Model Fit.

16. Hu, L.-T. \& Bentler, P. M. 1998. Fit Indices In Covariance Structure Modeling: Sensitivity To Underparameterized Model Misspecification. Psychological Methods, 3, 424.

17. Jayaram*, J., Kannan, V. R. \& Tan, K.-C. 2004. Influence Of Initiators On Supply Chain Value Creation. International Journal Of Production Research, 42, 4377-4399.

18. Kline, R. B. 2005. Principles And Practice Of Structural Equation Modeling 2nd Ed. New York: Guilford, 3.

19. Kline, R. B. 2011. Convergence Of Structural Equation Modeling And Multilevel Modeling. Na.

20. Li, Y., Sun, A., Su, S., Zhao, P., Cui, Z. \& Zhu, H. 2011. Deletion Of The Meq Gene Significantly Decreases Immunosuppression In Chickens Caused By Pathogenic Marek's Disease Virus. Virology Journal, 8, 1-8.

21. Luu, L., Bettridge, J., Christley, R. M., Melese, K., Blake, D., Dessie, T., Wigley, P., Desta, T. T., Hanotte, O. \& Kaiser, P. 2013. Prevalence And Molecular Characterisation Of Eimeria Species In Ethiopian Village Chickens. Bmc Veterinary Research, 9, 1-7.

22. Mcpherson, M. C., Cheng, H. H. \& Delany, M. E. 2016. Marek's Disease Herpesvirus Vaccines Integrate Into Chicken Host Chromosomes Yet Lack A Virus-Host Phenotype Associated With Oncogenic Transformation. Vaccine, 34, 5554-5561.

23. Othman, I. \& Aklilu, E. Marek's Disease Herpesvirus Serotype 1 In Broiler Breeder And Layer Chickens In Malaysia, Veterinary World, 12 (3): 472-476. 2019. Abstract. 
24. Pituch, K. A. \& Stevens, J. P. 2015. Applied Multivariate Statistics For The Social Sciences: Analyses With Sas And Ibm's Spss, Routledge.

25. Purchase, H. \& Biggs, P. 1967. Characterization Of Five Isolates Of Marek's Disease. Research In Veterinary Science, 8, 440-453.

26. Raykov, T. 1997. Estimation Of Composite Reliability For Congeneric Measures. Applied Psychological Measurement, 21, 173-184.

27. Raykov, T. \& Marcoulides, G. A. 2006. Estimation Of Generalizability Coefficients Via A Structural Equation Modeling Approach To Scale Reliability Evaluation. International Journal Of Testing, 6, 8195.

28. Sambo, E., Bettridge, J., Dessie, T., Amare, A., Habte, T., Wigley, P. \& Christley, R. M. 2015. Participatory Evaluation Of Chicken Health And Production Constraints In Ethiopia. Preventive Veterinary Medicine, $118,117-127$.

29. Şandru, C. D., Brudaşcă, G. F., Spînu, M., Niculae, M., Ungvari, A. \& Uricaru, A. 2008. Infecţlia Cu Virusul Bolii Lui Marek Afectează Imunitatea Celulară Nespecifică \$̧1 Specifică. Analele Societatii Nationale De Biologie Celulara, 13.

30. Sarstedt, M. \& Mooi, E. 2014. A Concise Guide To Market Research. The Process, Data, And, 12.

31. Schat, K. A. 2016. History Of The First-Generation Marek's Disease Vaccines: The Science And LittleKnown Facts. Avian Diseases, 60, 715-724.

32. Sipahi, B., Yurtkoru, E. \& Çinko, M. 2010. Data Analysis With Spss In Social Sciences. Istanbul: Beta Publishing.

33. Westfall, P. \& Henning, K. 2013. Texts In Statistical Science: Understanding Advanced Statistical Methods. Boca Raton, Fl: Taylor \& Francis.

34. Woźniakowski, G. \& Samorek-Salamonowicz, E. 2014. Direct Detection Of Marek's Disease Virus In Poultry Dust By Loop-Mediated Isothermal Amplification. Archives Of Virology, 159, 3083-3087.

35. Zhou, X., Wu, S., Zhou, H., Wang, M., Wang, M., Lü, Y., Cheng, Z., Xu, J. \& Ai, Y. 2019. Marek's Disease Virus Regulates The Ubiquitylome Of Chicken Cd4+ T Cells To Promote Tumorigenesis. International Journal Of Molecular Sciences, 20, 2089.

\section{Figures}




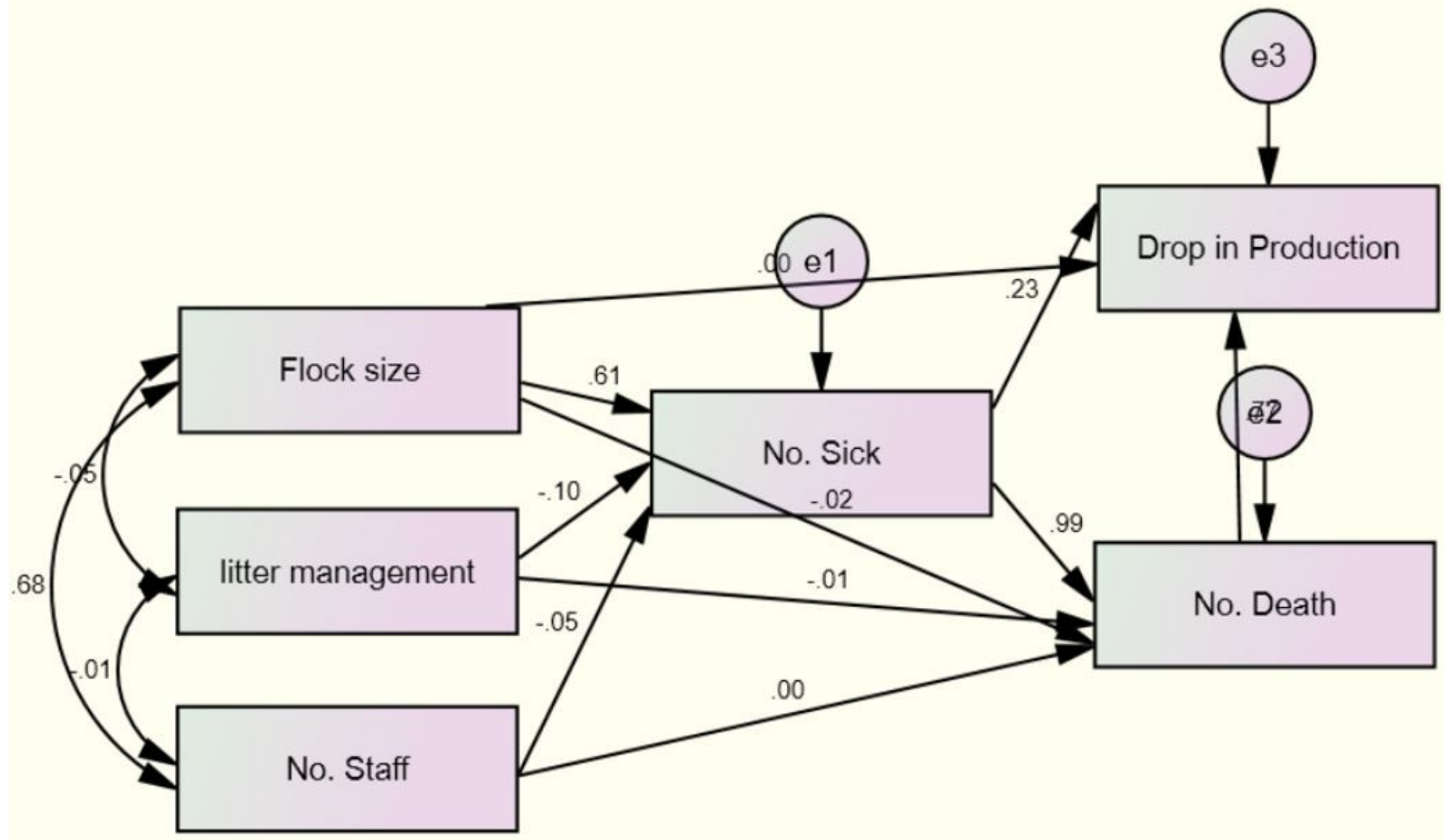

Figure 1

The constructs of SEM model in the performed factors analyses on the intention to implement MD control measures. 